\title{
Collage-Based Research and Design
}

\author{
Sarah Wehmeyer
}

Editorial Summay: In her contribution »Collage-Based Research and Design«, Sarah Wehmeyer addresses the distinct differentiation between design-based and design-related forms of investigation in architecture. Hereby, she fosters reflexive design and research processes and practices as sources of "design-specific knowledge". In this regard, she highlights applied artistic and superordinate theoretical aspects as well as discusses practical skills and scientific capacities inherent to the medium of collage as an architecture-specific tool for design and research. This contribution can be read as a precise and distinct examination of the collage as an artifact, media of design, knowledge creation, and communication, and as an alternative - artistic-reflexive methodological approach to research in architecture. [Katharina Voigt]

Keywords: Collage; Artistic Concepts and Reflection; Reflexive Design; Reflexive Research Practice; Design-Specific Knowledge; Media of Knowledge; Image as Knowledge Component.

\section{Architectural Ways of Researching?}

Due to a new self-understanding in the context of the academic landscape, architects are increasingly showing an interest in not only defining design as a generative and integrative field of research, but also in seeking their own »architectural« ways of researching. Discourses of both design-based and design-related research play a central role in this context. From varying perspectives, they discuss new notions of traditional research definitions that are rooted in the methodological framework of the humanities and other theoretical research attempts. Further, they contemplate their methodological expansion and connection to the wider spectrum of processes, practices, and instruments offered by the core competence of architecture: the design. While some positions hereby focus on the design (process) itself as the main methodological basis (Fraser 2013; Weidinger 2013), other formats, such as the Reflexive Design, highlight possible crossovers and interactions of design and research as generative epistemological processes (Buchert 2014; Buchert 2016; Buchert 2018). 


\section{Research-Oriented Design}

Such a coevolutive approach as a specific form of architectural research is promoted by the concept of research-oriented design [forschendes Entwerfen]. The term, which may initially appear paradoxical, describes an intended procedure that connects the search for compositional order the design - with the search for design-specific knowledge - the research (Buchert 2011: 77-78). It is assumed that the architect not only aims to realize a built space or object, but also to raise specific questions and investigate them during the design process and beyond. These questions may be individually design- or project-related and may concentrate on collective social, economic, or other topics of discussion, as well as address overarching aspects of design.

Correlative + Reflexive. Research-oriented design does not seek to scientificize or rationalize the design process, as was attempted in the 1960 s with the Design Methods movement (Schrijver 2014: 61-63). Rather, the intention is to emphasize the potential of the complex ordered design process as an iterative development, in which, as Donald Schön describes it, phases of analytical, reflective, and synthetic activities are mutually connected and repeated (Schön 1991: 94-95, 280). A further key characteristic concerns Michael Polanyi's concept of tacit knowledge: this never completely tangible network of images, analogies, and syntheses, which precedes, supports, and exceeds the design process (Buchert 2011: 79-83; Polanyi 1966). It manifests itself in the interaction between different design practices and instruments, in (un)built products as well as in individual archives. As designers in creative phases primarily concentrate on the desired outcome, the generative potential of this specific knowledge plays an accompanying, yet unnoticed role (Schön 1991: 282). Research-orientated design strives for conscious reflexive phases of alienation, review, consolidation, and abstraction that focus on the designed object as well as on the architect and their actions to gain access to individual design-related insights (Ammon/Froschauer 2013: 16; Buchert 2014:33, 47). In this manner, the twofold motivated search should not be understood as research linked to a singular design project. Instead, in its reflexive capacity, it describes a project-overlapping research ambition, which includes both the (further) development of different project conceptions as well as the concretization of individual basic conceptions. 
Instruments. Which instruments and practices support and catalyze the research-orientated design as a medial and/or methodological constant? How is design-specific knowledge captured in material and visual objects and how do these research results become accessible and applicable to others? While the tools of the architect and their influence on the design process have already been addressed in various publications (e.g. Gänshirt 2021), the investigation of their formative role at the interface of design and research processes as well as their knowledge transfer qualities remains in its infancy. Robin Evans for instance tried to decipher the correlations between architects, drawing projections, collective spatial ideals, and the perception of the built object, both linguistically and with his own graphic illustrations (Evans 2011: 192). Subsequent positions have since emerged, exploring the qualities of architectural drawing beyond its function of constructive support and means of representation (Kienbaum 2016). Similarly, the notion of the model as a tool for the production of ideas with research qualities (Oechslin 2011; Ursprung 2013) as well as architectural photography receive increasing focus in scientific observation (Schrijver 2014: 63-65). In the quest for hitherto unknown research-orientated design instruments, both our own everyday design practices as well as the work of individual architects, since modernity to the present day, can serve as exciting sources. Against this background, this dissertation (re-)discovers the collage as a basis for architectural action and thought. The aim is to identify the practical skills and scientific capacities that the collage generates as an architecture-specific design and research tool.

\section{Re-Think Collage!}

Collages are currently experiencing a comeback as an alternative form of architectural visualization in addition to established forms of architecture representations such as maps, plans, and renderings. Spatial atmospheres are increasingly created through digitally or analogously generated layering of different, abstract colors or material surfaces and fragments of pictures. Beyond the visual succinctness of these images, special attention must be paid to certain contemporary architects, such as OFFICE and Dogma from Brussels or the Mexican Tatiana Bilbao; such architects demonstrate - in their individual interaction with collage - an intensified artistic and research-orientated access to the design process. The ongoing dissertation ties in with this point and focuses on the potential 
that collage and collaging offer for conceptualizing and researching on architecture and urban space, as well as for reflecting on individual design competences, ideals and values and develop them further. Moreover, the question arises whether and how the collage - as a reflexive approach to creative processes - implicitly or explicitly supports the genesis of designspecific knowledge. Situated in a phenomenological hermeneutic research tradition, the dissertation is structured in different methodical steps. The main part is conceived as a case study analysis of the already mentioned architectural firms. Through scientific investigation and supplementary interviews, it will be explored when and with which perspective they use the digitally or analogously composed collage as a form of visualization, design instrument, or research medium. Furthermore, the aim is to address the collage not only as an object of research, but also to prove it as a practice itself. The test field consists of a collage-based design and research study in conjunction with the doctoral thesis; it creates the space to rethink and examine the methods and objectives of the architects and to expand the research findings regarding the authors' own work as architects and theorists.

The theoretical and practical exploration of the collage is tied to the discourses on research-orientated design as a specific facet of reflexive design. As a scientific classification of the collage as a knowledge-generating and -mediating instrument is missing in this research context, the scope of possibilities and potentials will be discussed within the framework of the dissertation and in excerpts in this article.

\section{Collage-Based Research and Design}

A collage is not a simple illustration of the present or future world. Rather, it creates its own pictorial reality with simultaneous layers of different meanings and realisms, evoked by the layered coexistence of image fragments from different contexts. This recycling of fragments and statements as well as the provoked openness of interpretation is often combined with a critical intention that addressed issues of society, design, and perception (Schneede 2001: 77). The specific dialectic of the collage has been interpreted in many ways in the fine arts since the first papier collé (Jürgens-Kirchhoff 1984: 42) and has just as often been a graphic and conceptual reference for architects (MoMA 2014; Shields 2013). 
Retrospective. The fact that some of these characteristics even enabled individual architects to gain new insights into spatial forms of expression, as well as into their own design practices and values, was conveyed in several architecture theory publications. Neil Levine and Martino Stierli show, for example, that the collage-specific interplay of flatness and depth has been a fundamental practice for Mies to understand, develop, and communicate his specific spatial principles, such as the staging of material surface as space-defining walls (Levine 1998; Stierli 2011: 409-410). Based on the creative actions of Superstudio and Archizoom, Marie Stauffer has demonstrated how the collage is used as a tool alternative to language in its interface between reality and vision. Firstly to deal more independently with design and social issues, and secondly to provoke public discourse by publishing the ideas gathered as a common visual shock therapy: the negative utopia of total urbanization and consumption as manifested in the Continuous Monument or the No-Stop City (Stauffer 2007: 10-19).

Contemporary Applications. »A Grammar for the City« (2005) developed together by OFFICE and Dogma (see fig. on next page) is one interesting example for a current collage-based research and design project. The design for a new South Korean capital ${ }^{1}$ is both a competition entry as well as a component of a wider context of projects and collages (re)searching design strategies that serve as architectural solutions to uncontrolled urbanization and loss of public space. The architects consciously refer to already available design-related knowledge - the rational positions of the 1960 - and apply it with the prospect of further developing their own design-specific insights. The intention is the continuous improvement of their individual typologies »building-as-wall« und »square-as-room « as possible answers to their own ideals (Aureli/Tattara 2017: 61; Borasi 2017: 11-13; Wehmeyer 2018). Thus, in the project series, including »Stop City« and »Lokomotiva 3 « by Dogma or "Tower and Square« by OFFICE (see fig. on next page), accompanying research activities can be identified in which the studies of urban vocabulary and the design of urban architecture and spaces become one.

1 In 2005, a competition was held to develop a new multi-functional administrative city in South Korea, in response to the enormous dominance exerted by the metropolitan area of Seoul and in an attempt to foster decentralization. 

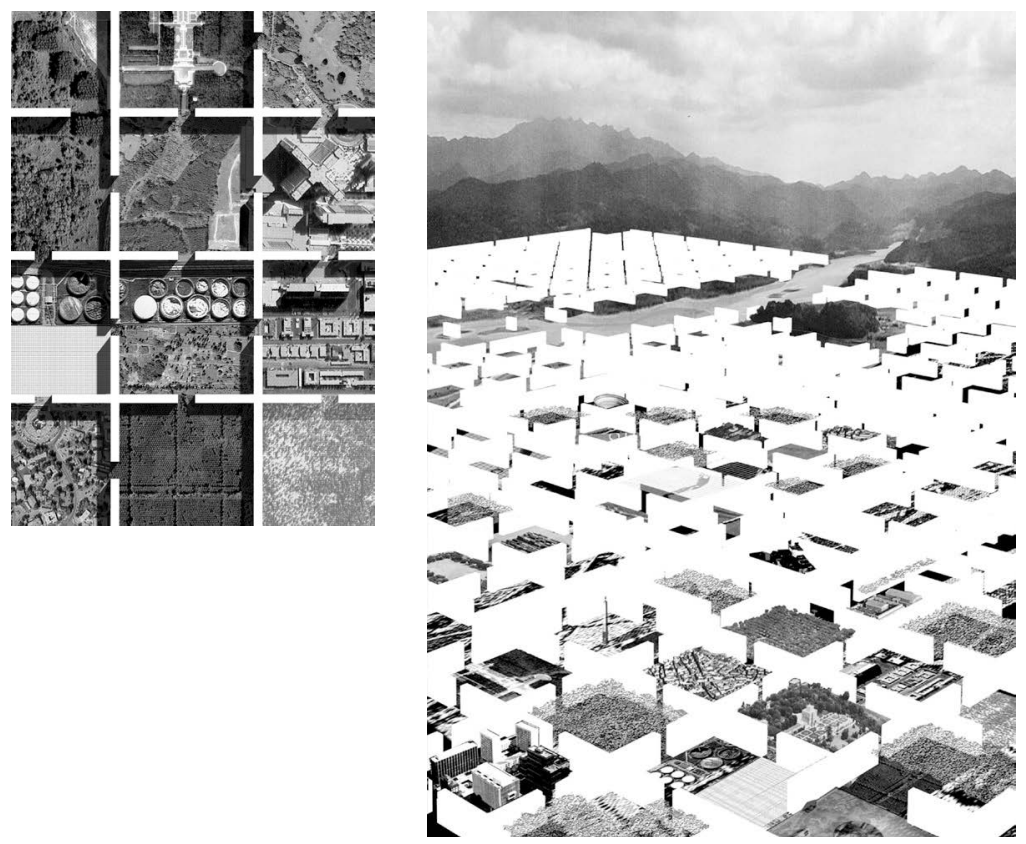

Urban walls and rooms

A grammar for the city (2005)

OFFICE + DOGMA

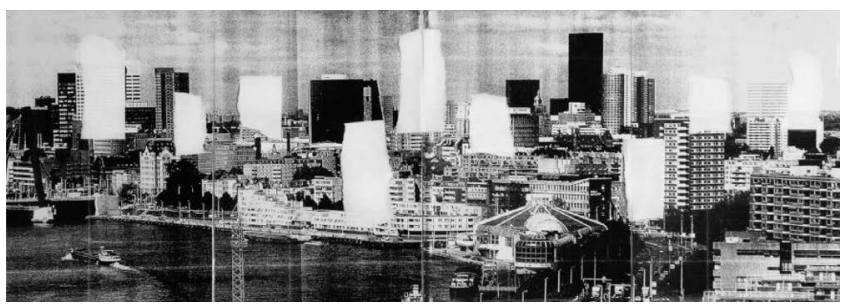

Towers + squares (2004)

OFFICE o9 
To convey the gained insights not only linguistically, but also graphically, OFFICE and Dogma utilize the collage to display a visually striking image. The white surface is chosen to symbolize and accentuate the role of architecture as a structuring "wall« that acts in the background, while the monochrome or color-intensive photographic images present the square interspaces as generous "rooms « open to urban unfolding (Aureli/Tattara 2017: 61). The different atmospheres evoked by this monumental and yet restrained design grammar would have been difficult to describe in words but become visually explicit through collage. However, the question still remains of how these aspects of design-related knowledge may be generated in interaction with collage. When juxtaposing intentions and pictorial rhetoric of the contemporary and the earlier collages, several inspiring observations can be made.

\section{Cognitive Performances}

Visual Training. A distinct feature of these contemporary collages is the carefully composed dialogue of two components: Abstract white surfaces in combination with photographic backgrounds create the specific interplay between planarity and depth that Mies already successfully used to train his perception. OFFICE and Dogma also appear to activate the process of composing the image space as a practice for honing their own design-related competences. The interplay between two-dimensional surfaces and three-dimensional space acts, in this context, as a method of training their perception of urban scenes as spaces and walls.

Critical Image. Correspondingly, it appears that contemporary architects, similar to Superstudio and Archizoom, use collages in their original artistic intention as critical mirror images of reality. The floating state between abstraction and realism initiates a new, more exaggerated and dramatic perspective of the omnipresent and familiar theme of urbanization. The recipient is left in uncertainty as to whether the vertical densification and absolute definition of the city's basic form via walls and towers represents an already existing or a future state of habitat. It also remains unclear whether the white surfaces display serious or ironic typological solutions. In this regard, the collage reveals its fundamental quality as an artistic artefact by leading the recipient to new insights and knowledge through confrontation, critical self-reflection and association. It calls for thinking beyond the written and visual manifests, beyond the here and now, and rather for 
relating one's own stance and action to the environment and fellow human beings, with regard to the past, present, and future. In this way, the collage - as well as an architecture - mediates between the world and mankind, it points out aspects that cannot be described methodically or conceptually (Buchert 2011: 44-47). To create this mediation, the collage requires that complex contents are abstracted into striking but also mind-opening visual statements. As Evans already recognized in relation to projections (cf. Evans 1995), the collage provokes the genesis of new findings through focusing, abstracting, and transferring ideas to paper, more in the process of making than explicitly intended.

Reflexive Components. Keeping the collage in mind as a "practice«, further possibilities for the genesis of design-related insights emerge with regard to Donald Schön. The urbanist and sociologist questions how practitioners examine themselves in action without being paralyzed by the complexity of information, dependencies, and background knowledge that are usually handled implicitly. Observing the architect, Schön detects the everyday practice of sketching as intuitive yet unrecognized conscious access to reflection and, in this sense, as a targeted way of grasping aspects of silent knowledge. Schön describes how hand drawing slows down the process of designing and at the same time constructs a parallel, "virtual world « on paper, in which the architect finds the time to reframe, vary, or experiment with their ideas (Schön 1991: 277-279). Viewing the process of collaging, one could interpret the different steps - from selecting and cutting out to layering and relating - as similar generative moments of deceleration. Aware of this capacity, architects could intentionally use the practice as a reflexive tool to establish personal think tanks in uncertain or stagnating situations of designing or researching and to restructure thoughts and receive new creative input. The persistent but varying creation of collages, as can be observed in the case studies, is understood here as a first indication that Dogma and OFFICE may have intuitively appropriated this potential. Furthermore, it may imply that the architects use collages to document and archive their designs, as well as their design-related knowledge. Due to their high level of abstraction, collages can therefore be read as individual image studies and visual knowledge archives, which allow the architects - during the process and afterward - to distance themselves from their work in order to examine, compare, and rethink ideas and syntheses. It seems as if the collage is now also consciously integrated as an »object« into the design and research 
processes in order to enable its reflexive qualities of supporting the self-critical development of stances and values. As collages are constantly published in exhibitions and publications, they can also be understood as a collectively accessible knowledge pool that we can refer to.

\section{The Difficult Whole}

Collage and Research. The knowledge-generating and -communicating potentials of the collage identified so far appear to simultaneously reveal their limits. Even if the collage is based on rational actions, it reflects a subjective point of view and allows only limited direct inference of the theories behind the picture or of a clear documentation of findings. It »encodes« the researcher's message in a certain visual way, so that complementary, descriptive methods are required. Moreover, it seems beneficial to have some prior knowledge of the ideal dimensions of collages in order to be able to interpret and use them as a critical instrument of analysis and representation. However, it is precisely its characteristic as a complex entity that makes the collage so interesting for research in architecture, offering an architecture-specific access to investigate research questions and create research findings. In their complementary interaction of objective and subjective factors, in their reflexive and artistic dimension and finally in their associative effect, collages embody fundamental qualities of designing and receiving architecture.

Design and Research. In the quest for discipline-specific ways of researching, the activation or adoption of design practices as research practices can forge new perspectives. Yet the limits and risks of such approaches should always be integrated into the discourse. Simply equating design and research could lead to a loss of relevance for theory, often critically perceived in practice anyway. The compulsive attempt to embed design in research, in turn, could overwhelm especially young scholars in their PhD projects. This raises the question of whether a »classical dissertation that includes research inquiries into the phenomenological, i.e. also about the interaction of subject and object, is not already architecture-specific research. However, alternative research approaches, exemplified by the collage, clarify the enriching potential for reflection and communication that the interplay of theoretical and practice-based practices as well as verbal and visual patterns offers for (architectural) research. 
References

Ammon, Sabine/Froschauer, Eva Maria, eds. (2013): Wissenschaft Entwerfen: Vom forschenden Entwerfen zur Entwurfsforschung der Architektur, Paderborn: Wilhelm Fink Verlag.

Aureli, Pier Vittorio Aureli/Tattara, Martino (2017): »Is this a city?«, in: Kersten Geers, David van Severen (eds.), OFFICE Kersten Geers David van Severen, Volume 1 (exhibition catalogue, BOZAR Centre for Fine Arts Brussels, 2016), Cologne: Verlag der Buchhandlung Walther König, 61.

Borasi, Giovanna (2017): »Hunting for the Present in the Past«, in: Kersten Geers/David van Severen (eds.), OFFICE Kersten Geers David van Severen, Volume 1, (exhibition catalogue, BOZAR Centre for Fine Arts Brussels, 2016), Cologne: Verlag der Buchhandlung Walther König, 11-13.

Buchert, Margitta (2011): »Formen der Relationen: Entwerfen und Forschen in der Architektur«, in: Ute Frank/ Helga Blocksdorf/Marius Mensing/ Anca Timofticiuc, EKLAT: Entwerfen und Konstruieren in Lehre, Anwendung und Theorie, Berlin: Universitätsverlag TU Berlin, 76-85.

Buchert, Margitta (2014): Reflexives Entwerfen. Entwerfen und Forschen in der Architektur / Reflexive Design. Design and Research in Architecture, Berlin: Jovis.

Buchert, Margitta (2014): »Reflexive Design?«, in: Margitta Buchert, Reflexives Entwerfen. Entwerfen und Forschen in der Architektur/Reflexive Design. Design and Research in Architecture, Berlin: Jovis, 24-49.

Buchert, Margitta (2016): Praktiken reflexiven Entwerfens. Entwerfendes Forschen/Forschendes Entwerfen in Architektur und Landschaft, Berlin: Jovis.

Buchert, Margitta (2018): Processes of Reflexive Design, Berlin: Jovis.
Evans, Robin (2011[1995]): The Projective Cast. Architecture and Its Three Geometries, Cambridge, MA: MIT Press. Here, in particular, the last chapter „Conclusion. The Projective Cast«.

Fraser, Murray, ed. (2013): Design Research in Architecture: An Overview, Farnham: Ashgate Publishing.

Gänshirt, Christian (2021): Tools for Ideas. Introduction to Architectural Design, expanded and updated edition, Basel: Birkhäuser.

Jürgens-Kirchhoff, Annegret (1984): Technik und Tendenz der Montage in der bildenden Kunst des 20. Jahrhunderts. Ein Essay (Kunstwissenschaftliche Untersuchungen des Ulmer Vereins, Verband für Kunst und Kulturwissenschaften, 7), Gießen: Anabas.

Kienbaum, Laura (2016): »Zeichnen in der Forschung«, in: Margitta Buchert, Praktiken Reflexiven Entwerfens. Entwerfendes Forschen, Forschendes Entwerfen, Berlin: Jovis, 115-127.

MoMA (2014): »Cut 'n' Paste: From Architectural Assemblage to Collage City«, exhibition July 10, 2013-January 5, 2014; cf. https://www.moma.org/calendar/ exhibitions/1343, accessed February 19, 2021.

Levine, Neil (1998): »The Significance of Facts: Mies's Collages Up Close and Personal«, in: Assemblage: A Critical Journal of Architecture and Design Culture, no. 37 , 35-101.

Oechslin, Werner (2011): »Architekturmodell. Idea materialis«, in: Wolfgang Sonne (ed.), Die Medien der Architektur, Munich: Deutscher Kunstverlag, 131-155.

Polanyi, Michael (1966): The Tacit Dimension, London: Routledge \& Kegan Paul.

Shields, Jennifer A. E. (2013): Collage and Architecture, New York: Routledge. 
Schneede, Uwe M. (2001): Die Geschichte der Kunst im 20. Jahrhundert. Von den Avantgarden bis zur Gegenwart, Munich: C. H. Beck.

Schön, Donald (1991[1983]): The Reflective Practitioner. How Professionals Think in Action, Abingdon: Routledge.

Schrijver, Lara (2014): »Architectural Knowledge: Method or Mystery?«, in: Margitta Buchert (ed.), Reflexive Design. Design and Research in Architecture, Berlin: Jovis, 50-71.

Stauffer, Marie Theres (2007): Figurationen des Utopischen. Theoretische Projekte von Archizoom und Superstudio, Berlin/Munich: Deutscher Kunstverlag.

Stierli, Martino (2011): »Mies Montage: Mies van der Rohe, Dada, Film und die Kunstgeschichte «, in: Zeitschrift für Kunstgeschichte 74(3), 401-436.

Ursprung, Philip (2013): „Exponierte Exponate. Herzog \& de Meuron«, in: Sabine Ammon/Eva Maria Froschauer (eds.), Wissenschaft Entwerfen: Vom forschenden Entwerfen zur Entwurfsforschung der Architektur, Paderborn: Wilhelm Fink Verlag, 289-305.

Weidinger, Jürgen (2013): Entwurfsbasiert Forschen, Berlin: Universitätsverlag TU Berlin.

Wehmeyer, Sarah (2018): »Collages Interactions «, in: Margitta Buchert (ed.), Processes of Reflexive Design, Berlin: Jovis, 124-140. 
